\title{
Everything's Better in Moderation: Young Women's Gender Role Attitudes and Risky Sexual Behavior
}

\author{
Tamara G.J. Leech \\ Indiana University-Purdue University, Indianapolis, Indiana
}

\begin{abstract}
Purpose

This study examines the association between gender role attitudes and risky sexual behavior among young women. Previous studies have posed seemingly contradictory arguments: that either traditional attitudes or egalitarian attitudes are associated with riskier behavior.
\end{abstract}

\section{Methods}

Data are based on the children of the National Longitudinal Survey of Youth, representing 520 sexually active 18-19-year-old women. Propensity radius matching was used to assess differences in rates of multiple sexual partners and sex outside of a committed relationship.

\section{Results}

Relative to moderate gender role attitudes, both egalitarian gender role attitudes and traditional gender role attitudes are associated with higher rates of risky sexual behavior. Both women with egalitarian role attitudes and those with traditional role attitudes have about a $10 \%$ higher prevalence of risky behavior compared to women with more moderate gender role attitudes.

\section{Conclusion}

Existing, seemingly contradictory contentions about the relationship between gender role attitudes and risky sexual behavior may be more coherent than they seem. By shifting focus from risk to protection, the results suggest that moderate gender role attitudes are protective against risky sexual behavior. Future studies should investigate the causal mechanisms and intervention implications of this protective relationship.

Keywords: Gender role; Premarital sex behavior; Women's role

This is the author's manuscript of the article published in final edited form as:

Leech, T. G. J. (2010). Everything's Better in Moderation: Young Women's Gender Role Attitudes and Risky Sexual Behavior. Journal of Adolescent Health, 46(5), 437-443.

http://doi.org/10.1016/j.jadohealth.2009.10.012 


\section{Everything's Better in Moderation: Young Women's Gender Role Attitudes and Risky Sexual Behavior}

Gender roles and gender role attitudes continue to greatly influence American adolescents' everyday experiences, especially as they relate to social outcomes that determine power within relationships (such as women's economic standing and exposure to violence). Girls' career choice goals [1] and women's labor market experience [2] and monetary earnings [3] are heavily shaped by their gender role attitudes. In addition, gender role attitudes have some bearing on women's exposure to violence. Traditional gender role attitudes among men have been found to underlie rape scripts [4], and traditional beliefs among women are associated with tolerant perceptions of men's violence toward women [5].

Despite this connection to power dynamics within relationships, the influence of young women's gender role attitudes on risky sexual behavior in the United States remains unclear. Various scholars have argued that either traditional [6], [7], [8], [9], [10], [11] and [12] or egalitarian gender role attitudes [13] and [14] could be associated with risky sexual behavior among young women. However, a majority of these studies are based on international populations [6], [8], [10], [11] and [12] or are confined to male samples in the United States [15] and [16]. There is a paucity of empirical research testing these ideas — individually or in conjunction — among women in the United States. Therefore, this article examines the relationship between gender role attitudes and risky sexual behavior - specifically, rates of casual sex and multiple sex partners — in a national sample of at-risk young women.

\section{The Risk of Traditional Gender Attitudes}

Scholars suggest that a belief in traditional feminine roles can lead to risky sexual behavior in two primary ways: (1) through hyperfemininity and (2) by discouraging women from successfully negotiating sexual encounters. Murnen and Byrne [17] outline three characteristics of hyperfeminine women: (1) self-worth is largely dependent on relationships with men, (2) sex is used as a tool to gain or maintain relationships, and (3) traditional masculine behavior is preferred in a mate. It is traditionally suggested that women limit sexual partners to potentially long-term mates [18], but through exposure to hyperfemininity, many young women are simultaneously confronted with the idea that sex can and should be used as a tool to gain and maintain relationships. Thus, traditional attitudes in the form of hyperfemininity can increase the likelihood of multiple sex partners and sex outside of (or prior to) committed relationships [17].

Furthermore, traditional female roles discourage women from communicating and negotiating in sexual encounters [7]. The sexual norms and stigmas accompanying traditional gender role attitudes discourage women from discussing sexual situations with friends or family because they may be perceived as having too much experience-based knowledge [7] and [9]. In this way, strong, traditional gender role attitudes may limit women's sexual capital - that is, social networks and self-efficacy [19] — and thus increase the likelihood of risky sexual behaviors.

\section{The Risk of Egalitarian Attitudes}


A large body of literature shows that men who internalize traditional definitions of masculinity are more likely to have multiple sexual partners in the last year, a less intimate relationship at last intercourse, and participate in sexual coercion [14], [15], [16] and [20]. This evidence provides the theoretical basis for hypotheses that egalitarian gender attitudes among young women are associated with risky sexual behavior. The assumption is that egalitarian attitudes among women translate into the adoption of masculine gender roles and/or sexual scripts [21]. This assumption is questionable for some populations, but is increasingly more likely during middle to late adolescence [22]. During this formative stage, some girls who are in the initial stages of questioning established gender norms may attempt to enact "egalitarian” roles by adopting traditionally masculine behaviors [23].

In this way, the risks related to egalitarian gender attitudes partially originate with the polarization of gender within U.S. society. Bem provides a succinct description of gender polarization: "First, it defines mutually exclusive scripts for being male and female. Secondly, it defines any person or behavior that deviates from these scripts as problematic" (p. 81) [24]. Within this polarized cultural context, the only socially authorized way to exhibit a "nonfeminine" identity would be to turn to masculine behavior.

To date, few studies have directly investigated the connection between egalitarian attitudes and multiple partners or casual sex among adolescent women. One study of young Australian women reports that women with masculine personality traits, as well as those who support egalitarian gender roles, are more likely to have multiple sex partners [13]. However, within a sample of female college students in the United States, Shearer et al. find no relationship between gender attitudes/masculine ideology and multiple partners (although the results are significant for male students) [14].

\section{Specific Aims}

Thus, there is limited, direct empirical support for the contention that either polar end of the spectrum of gender role attitudes - egalitarian or traditional attitudes — is associated with riskier health behaviors. This study aims to simultaneously investigate these two seemingly contradictory propositions. I combine the two disjointed literatures to form one conceptual model (Figure 1) positing that both ends of the spectrum are associated with risk.

First, the sexual behavior of women with extremely traditional gender role attitudes is compared with that of women with moderate gender role attitudes. Second, the sexual behavior of women with extremely egalitarian gender role attitudes is compared with that of women with moderate gender role attitudes. It is hypothesized that both groups with extreme attitudes - those with traditional and those with egalitarian attitudes - will have relatively higher rates of multiple sex partners and sex outside of a committed relationship than will the more moderate group.

\section{Methods}

The data for this study are from the National Longitudinal Survey of Youth (NLSY). The NLSY is a biannual panel study that began in 1979. Originally, the study followed a nationally representative sample of 12,686 people aged 14-21 years. Beginning in 1986, data were 
collected on all children ever born to women in the NLSY sample through self-reports and mother interviews. The analyses in the present study rely upon data on these children, that is, on the data from the Young Adult Survey. (For a complete discussion of the Young Adult Survey and the children of the NLSY in general, see [25]). As such, the sample consists of 520 sexually active women aged 18-19 years in 2000 or 2002.

\section{Participants}

Table 1 presents the participants' relevant sociodemographic characteristics. Respondents are nearly evenly divided between White [252] and African American [268] women, but with appropriate weights they constitute $77 \%$ and $23 \%$ of the sample, respectively. On average, respondents initiated sexual activity at age 16 . Furthermore, the table shows that the participants constitute a demographic group that may be particularly vulnerable to risky sexual behavior [26] and [27], as mean household income is below the national average (at \$42,534) and nearly a third of the women were born to teen mothers.

\section{Measures}

\section{Gender role attitudes}

Gender role attitudes were measured according to an established scale within the NLSY [27]. Respondents indicated degree of agreement with five statements about gender roles on a 4-point Likert scale: "The place of women is in the home"; "A wife with a family has no time for employment”; "A working wife feels more useful”; "Traditional husband/wife roles are best”; and "Women are happier in traditional roles" $(\alpha=.81)$.

Scores from all of these questions were averaged to produce one index ranging from 1 to 4 , with higher scores representing stronger beliefs in traditional gender roles. To more directly reflect the typical theoretical discussion that bifurcates gender role attitudes into egalitarian and traditional, and to directly test the hypotheses that both egalitarian and traditional attitudes are associated with risk, the measure was then transformed into a categorical variable. The central $56 \%$ of scores were identified on this scale and labeled moderate gender attitudes. All scores below the 20th percentile were coded as egalitarian, and scores above the 76th percentile were labeled traditional. This coding scheme also represents a natural break in the data, as the cumulative percentages of the attitudes index increased from $20 \%$ to $42 \%$, and from $76 \%$ to $88 \%$.

\section{Risky sexual behavior}

Sexual behavior was assessed at age 18 or 19 (in 2000 or 2002). In the existing literature, indicators of "risky sexual behavior" vary according to the motivation of the study and the research method employed; thus, there is no standard measurement of the concept. Some of the more common indicators are non-use of condom, early sexual initiation, multiple sexual partners, and sex outside of a committed relationship. Beadnell [28] recommends that - for different purposes - any of five indicators be used to measure risky sex, and I use two of the items that he recommends: relationship with most recent sexual partner and number of partners in the past 
year. These two measures also conform to the previous theoretical discussion of egalitarian gender role attitudes and the adoption of masculine sexual norms [29].

Multiple sexual partners is represented by a dichotomous variable defined as having three or more sexual partners within the past year. Casual sex represents responses to the question, "What best describes your relationship with [your most recent sexual partner] when you last had sexual intercourse?” The dichotomous variable was coded affirmatively if the response was anything other than married, engaged, living together, or going steady. These two questions were also combined, in that risky sexual behavior constitutes a dichotomous variable representing either or both of these behaviors.

\section{Control variables}

Finally, there is good reason to suspect a spurious relationship between gender role attitudes and risky sexual behavior. Various individual characteristics, including age, religiosity, and race have been found to be related to gender role attitudes [30]. These same variables are among the strongest correlates of risky sexual behavior among adolescents [31]. A variety of family characteristics - most notably family structure, family income, mother's education, employment status, and age at first birth - have also been found to be correlated with both gender role attitudes [32] and sexual behavior among teens [33]. All these variables were controlled as part of the propensity score calculations, with the information on mothers' characteristics obtained from the mothers' own survey responses. The study design accounts for the potentially spurious effect of age, as all of the women's sexual behavior is measured at the same age.

Analysis

A propensity analysis was used to test for the "treatment effect" of gender role attitudes. Statistical control of variables in regression analyses can contribute to overparameterization when the number of confounders is large relative to the number of cases, as was true in this study. Propensity adjustment helps to overcome this limitation and is also less susceptible than regression analysis to collinearity [34].

The propensity scores represent the conditional probability (i.e., the "propensity") of having moderate gender attitudes given specific individual characteristics [35]. In this study, a logistic regression was used to estimate, for each participant, the probability of having moderate gender role attitudes according to characteristics known in the literature to be related to both gender attitudes and sexual behavior: religion, religiosity, race, family income, region of residence, rural vs. urban residence, mother's education, mother's employment status, and whether the mother was a teen mother. On the basis of this estimation, the conditional probability of having moderate attitudes (i.e., the propensity scores) ranges from .39 to .77, with a standard deviation of .06.

Radius matching was used to compare participants according to these propensity scores [36]. The sexual behavior of each adolescent with moderate gender attitudes was compared with that of all other participants within a standard distance (.06), approximately one standard deviation) of her propensity score. When these observations are combined, the resulting average difference in 
rates of risky behavior — that is, the average treatment effect on the treated — represents the "treatment effect" of moderate gender attitudes above and beyond the propensity to have moderate gender attitudes.

Survey weighting and imputation

Two percent (2\%) or less of the control variable observations was missing, and 15 cases were missing information on gender role attitudes. Missing data were imputed based on regressions using information from the most recent survey year (and demographic information). Furthermore, sampling weights were employed in the analyses to account for an oversampling of African Americans and sample attrition. After implementing these weights, the data represent females born to a nationally representative sample of women aged 14-21 in 1979.

\section{Results}

In the weighted sample, $63 \%$ of the sexually active teens report multiple sex partners or sex outside of a committed relationship within the past year. When broken into the component parts, just over one-third of the participants (36\%) report multiple partners in the past year and nearly half (47\%) report sex outside of a committed relationship. The sample's rate of multiple partners is similar to national averages of comparable behavior, in that $44 \%$ of $18-19$-year-old, sexually active women report two or more partners in the past year [37]. Estimates that $21 \%$ of sexually active 15-19-year-olds in the United States were not in a committed relationship at their first sexual experience represent the closest comparison to the sample's rate of sex outside of a committed relationship [37].

Propensity score adjustment

Table 2 reports the differences in the background characteristics of women according to their gender role attitudes. The table provides strong evidence that propensity matching effectively adjusted for these differences. Prior to the adjustments, women with traditional gender role attitudes were significantly more likely to be highly religious and to be the product of a teen mother. Women with egalitarian attitudes were more likely to be African American and to live in poverty. The propensity score matching resulted in much smaller differences on these characteristics, to the point that they are no longer statistically significant. To support these findings, further analysis (not shown) revealed that all of the covariates were balanced after adjustment, and that the matching accounts for approximately $52 \%$ (i.e., pseudo $\mathrm{R}^{2}=.52$ ) of the observed variation in the likelihood to have moderate gender role attitudes.

\section{Radius-matching analysis}

As discussed in the introduction, I hypothesized that both young women with extremely egalitarian attitudes and those with extremely traditional attitudes would have elevated rates of multiple sex partners and sex outside of a committed relationship compared with young women with more moderate gender role attitudes. Table 3 reports the propensity-adjusted, average rates of risky behavior specific to the teens' gender role attitude categories. When adjusted by propensity score, about $60 \%$ of the sample with moderate attitudes exhibit at least one risky 
behavior, while $69 \%$ of those with egalitarian attitudes exhibit these behaviors. The comparison specific to the group with traditional attitudes indicates that $70 \%$ of these teens report risky behaviors. Hence, there is support for both hypotheses. Both egalitarian and traditional gender role attitudes are associated with a significantly higher rate of risky sexual behavior (about a $10 \%$ increase). For confirmatory purposes, these two categories were compared with each other (in a separate propensity adjustment that is not shown, with traditional attitudes as the reference category). The resulting prevalence rates are reported and reveal no statistically significant difference (1\%) between teens with egalitarian and traditional attitudes.

When the two components of the risky sexual behavior measurement are analyzed separately, one minor difference is revealed. Women with traditional gender role attitudes have significantly higher rates of multiple sexual partners and sex outside of a committed relationship when compared with women with moderate gender attitudes. Women with egalitarian attitudes report higher rates of both behaviors also, but the rate of multiple partners is not significantly higher $(p=.08)$. Hence, the trend is consistent, but the difference is not significant.

\section{Discussion}

The main concern of this study is evaluating seemingly contradictory theoretical depictions of the relationship between gender role attitudes and risky sexual behavior among young women in the United States. After controlling for important covariates, the analyses reveal that both egalitarian attitudes and traditional attitudes are associated with higher rates of the general measurement of risky sexual behavior. Specifically, women with traditional gender role attitudes have a significantly higher prevalence of both multiple sexual partners and sex outside of a committed relationship. Those with egalitarian gender role attitudes also have a higher prevalence of both behaviors, but the elevated rates of multiple sexual partners are only marginally significant.

Combined, these results can be interpreted to support the idea that moderate gender attitudes among sexually active young women are associated with safer sexual practices, especially a lower likelihood of casual sex within the past year. In this study, moderate gender attitudes refer to scores on the gender role attitudes index that range between 2.5 and 3.75. On that scale, a score of 2 represents disagree, 3 represents neither agree nor disagree, and 4 represents agree. According to this measurement, then, moderate attitudes could indicate two different tendencies: consistent "fence straddling" or inconsistent responses. It is thus difficult to determine what gender schema the moderate gender role attitudes represent. It is clear, however, that "moderate" indicates a weaker gender schema — undecided, situation-dependent, or more fluid ideas about the roles of men and women - than the two "extreme" groups that more consistently reported strong beliefs about the proper role of men and women.

This type of fluidity in gender attitudes indicates a break with the polarized construction of gender previously discussed, such that for some girls challenges to traditional views of femininity do not have to result in the adoption of masculine roles. Women athletes may provide an example of this type of group, where strong identity as an athlete focuses attention on the body as a source of production for self-consumption; thus, challenging the typical feminine construction of the body as an object of consumption by males [38]. Miller et al. explain that, 
traditionally, American girls have been taught to be passive, nonconfrontational, and subservient in relationships. In sexual situations, this often translates into exchanging sex for affection or attention from males. However, their studies find that girls who participate in sports begin to challenge traditional gender stereotypes and gain social resources to draw upon in sexual negotiations [39]. These young women learn that their bodies can be used for their own, selfserving goals (as opposed to an object for male satisfaction.) Thus, participation in athletics serves as an example of a cultural context that allows challenges to the typical feminine role without adopting the traditional masculine role.

Through this and other similar constructions of femininity, moderate gender attitudes could protect against risky sexual behavior. The results of the present analysis indicate that the behavior of girls with extremely egalitarian or extremely traditional gender role attitudes are indistinguishable from each other, and the significant difference lies within the group that does not consistently or vehemently base their beliefs on either of these ideologies. It should also be recognized that this latter group represents a substantial portion of the sample: $56 \%$ of the young women. A large portion of our teenage girls seem to be forming nuanced attitudes about gender roles that are associated with safer sexual behavior. It may be fruitful to encourage girls to participate in groups and contexts that support these types of attitudes.

In addition, in the future it may be more appropriate for scholars to focus on moderation as protective. Further theoretical and empirical research is needed to explain the protective nature of moderate attitudes - that is, gender role attitudes that are fluid or malleable to situational context relative to extreme attitudes. In these efforts, researchers should be careful not to use variables that confound either of the extreme attitudes with more moderate ones. Limiting discussions and therefore measurements of gender attitudes to an indicator of, for example, egalitarian attitudes versus all others may not capture the elevated risk associated with traditional attitudes. Thus, scholars who remain interested in gender role orientations as an explanation for various social differences in risky sexual behavior — U.S. versus international, black versus white women, etc. — should take particular care to measure the concept of gender role attitudes on a spectrum.

Thus, the results provide important insight previously absent from the literature. However, the analysis has several limitations. The data are based on teens born to young mothers, and specifically to a large portion of mothers who were teens at first birth. Adolescents born to younger mothers could exhibit higher rates of health risk behavior for a variety of reasons, ranging from socioeconomic to social learning effects [26] and [40]. In this way, the results may be specific to the experience of at-risk populations. Furthermore, some of the measurements were not ideal: the gender role scale only represents one aspect of gender attitudes, and the measurement of risky sexual behavior does not include early sexual activity or condom use.

Nonetheless, the results serve as an initial step toward assessing the connection between attitudes and behavior among young women in the United States. They suggest that the focus on traditional gender attitudes or egalitarian attitudes as risky may be somewhat misguided. A slight change in theoretical orientation may be needed. Given the historic polarization of gender within our society, a view of moderate attitudes as protective would be more appropriate and could 
provide more useful guidance for formal and informal intervention and/or prevention efforts as well as future research efforts.

\section{Acknowledgments}

*This project and paper was supported by a SSRC-Mellon Mays Predoctoral Research Grant. I thank Dr. Jim House, Dr. Jeffrey Morenoff, Dr. Karen Martin, and Dr. Ben Hansen for their helpful comments on earlier drafts. 


\section{References}

[1] G.V. Gushue, M.L. Whitson. The relationship of ethnic identity and gender role attitudes to the development of career choice goals among Black and Latina girls. $\mathrm{J}$ Couns Psychol, 53 (2006), pp. 379-385.

[2] M.Y. Kan. Work orientation and wives' employment careers. Work Occup, 34 (2007), pp. 430-462.

[3] L.T. Stickney, A.M. Konrad. Gender-role attitudes and earnings: A multinational study of married women and men. Sex Roles, 57 (2007), pp. 801-811.

[4] M.H. Carroll, M.D. Clark. Men's acquaintance rape scripts: A comparison between a regional university and a military academy. Sex Roles, 55 (2006), pp. 469480.

[5] S. Herzog. Public perceptions of sexual harassment: An empirical analysis in Israel from consensus and feminist theoretical perspectives. Sex Roles, 57 (2007), pp. 579-592.

[6] L. Gavin, C. Galavotti, H. Dube, et al. Factors associated with HIV infection in adolescent females in Zimbabwe. J Adolesc Health, 39 (2006), pp. 596-612

[7] K. Greene, S. Faulkner. Gender, belief in the sexual double standard, and sexual talk in heterosexual dating relationships. Sex Roles, 53 (2005), pp. 239-251

[8] A. Klunklin, J. Greenwood. Buddhism, the status of women and the spread of HIV/AIDS in Thailand. Health Care Women Int, 26 (2005), pp. 46-61

[9] D. Lear. Sexual communication in the age of AIDS: The construction of risk and trust among young adults. Soc Sci Med, 41 (1995), pp. 1311-1323

[10] A.P. Martinez-Donate, M.F. Hovell, E.J. Blumberg, et al. Gender differences in condom-related behaviors and attitudes among Mexican adolescents living on the U.S.-Mexico border. AIDS Educ Prev, 16 (2004), pp. 172-186

[11] A.B. Robertsa, C. Oyun, E. Batnasan, et al. Exploring the social and cultural context of sexual health for young people in Mongolia: Implications for health promotion. Soc Sci Med, 60 (2005), pp. 1487-1498.

[12] C.S. Tang, C.Y. Wong, A.M. Lee. Gender-related psychosocial and cultural factors associated with condom use among Chinese married women. AIDS Educ Prev, 13 (2001), pp. 329-342

[13] J. Lucke. Gender roles and sexual behavior among young women. Sex Roles, 39 (1998), pp. 273-297. 
[14] C. Shearer, S. Hosterman, M. Gillen, et al. Are traditional gender role attitudes associated with risky sexual behavior and condom-related beliefs? Sex Roles, 52 (2005), pp. 311-324

[15] N.J. Bell, K. O'Neal, K. Feng, et al. Gender and sexual risk. Sex Roles, 41 (1999), pp. 313-332

[16] M.M. Copenhaver, S.J. Lash, R.M. Eisler. Masculine gender-role stress, anger, and male intimate abusiveness: Implications for men's relationships. Sex Roles, 42 (2000), pp. 405-414

[17] S. Murnen, D. Byrne. Hyperfemininity: Measurement and initial validation of the construct. J Sex Res, 26 (1991), pp. 85-106.

[18] P. Okami, T. Shackelford. Human sex differences in sexual psychology and behavior. Annu Rev Sex Res, 12 (2001), p. 186

[19] R. Michael. Sexual capital: An extension of Grossman's concept of health capital. J Health Econ, 23 (2004), pp. 643-652

[20] J. Pleck, F. Sonenstein, L. Ku. Masculinity ideology and its correlates. S. Oskamp, M. Costanzo (Eds.), Gender Issues in Contemporary Society, Sage, Newbury Park, CA (1993), pp. 85-110

[21] D. Obeidallah, R. Brennan, J. Brooks-Gunn, et al. Links between pubertal timing and neighborhood contexts: Implications for girls' violent behavior. J Am Acad Child Adolesc Psychiatry, 43 (2004), pp. 1460-1468

[22] J. Strough, J. Leszczynski, T. Neely, et al. From adolescence to later adulthood: Femininity, masculinity, and androgyny in six age groups. Sex Roles, 57 (2007), pp. 385-396

[23] M. Rebecca, R. Hefner, B. Oleshansky. A model of sex-role transcendence. A.G. Kaplan, J.P. Bean (Eds.), Beyond Sex-role Stereotypes: Readings Toward a Psychology of Androgyny, Little, Brown and Co, Boston, MA (1976), pp. 90-97

[24] S. Bem. The Lenses of Gender: Transforming the Debate on Sexual Inequality. Yale University Press, New Haven, CT (1993)

[25] L. Wu, A. Li. Children of the NLSY79: A unique data resource. Mon Labor Rev, 128 (2005), p. 59.

[26] J. Wilson. Teenage parenting: The long term effects for mothers and children. State, Local, and Intergovernmental Center, John F. Kennedy School of Government, Harvard University. John F. Kennedy School of Government, Cambridge, MA (1986) 
[27] S. Davis, T. Greenstein, J. Marks. Effects of union type on division of household labor: Do cohabiting men really perform more housework? J Fam Issues, 28 (2007), p. 1246

[28] B. Beadnell, D. Morrison, A. Wilsdon, et al. Condom use, frequency of sex, and number of partners: Multidimensional characterization of adolescent sexual risktaking. J Sex Res, 42 (2005), p. 192

[29] L. O'Sullivan, H. Meyer-Bahlburg. African-American and Latina inner-city girls' reports of romantic and sexual development. J Soc Pers Relat, 20 (2003), p. 221

[30] R. Harris, J. Firestone. Changes in predictors of gender role ideologies among women: A multivariate analysis. Sex Roles, 38 (1998), pp. 239-252

[31] N.S. Publications. Access to Health Risk Behavior in the United States: A StateBy-State Look at Teens and Adults. Publications NS, Ithaca, NY (2003)

[32] K. Kiecolt, A. Acock. The long-term effects of family structure on gender-role attitudes. J Marriage Fam, 50 (1988), pp. 709-717.

[33] V. Igra, C. Irwin. Theories of adolescent risk-taking behavior. R.J. DiClimente, W.B. Hansen, L.B. Ponton (Eds.), Handbook of Adolescent Health Risk Behavior, Plenum Press, New York, NY (1996), pp. 35-51

[34] D. Rubin, N. Thomas. Matching using estimated propensity scores: Relating theory to practice. Biometrics, 52 (1996), pp. 249-264

[35] P. Rosenbaum, D. Rubin. The central role of the propensity score in observational studies for causal effects. Biometrika, 70 (1983), pp. 41-55.

[36] S. Becker, A. Ichino. Estimation of average treatment effects based on propensity scores. Stata J, 2 (2002), pp. 358-377

[37] J.C. Abma, G. Martinez, W. Mosher, et al. Teenagers in the United States: Sexual activity, contraceptive use, and childbearing 2002. National Center for Health Statistics Vital Health Stat, 23 (2004), pp. 1-48.

[38] K.E. Miller, G.M. Barnes, M.J. Melnick, et al. Gender and racial/ethnic differences in predicting adolescent sexual risk: Athletic participation versus exercise. J Health Soc Behav, 43 (2002), pp. 436-450.

[39] K.E. Miller, D.F. Sabo, M.P. Farrell, et al. Sports, sexual behavior, contraceptive use, and pregnancy among female and male high school students: Testing cultural resource theory. Sociol Sport J, 16 (1999), pp. 366-387 
[40] R. Maynard. Kids Having Kids: Economic Costs and Social Consequences of Teen Pregnancy. Urban Institute Press, Washington, DC (1996). 
Table 1. Participants' sociodemographic characteristics, (weighted, $n=520$ )

\begin{tabular}{lccc}
\hline Mean & Cl & & \\
\hline \hline Race & & & .016 \\
\hline \hline White & .77 & $.74-.80$ & .016 \\
\hline \hline African American & .23 & $.20-.26$ & 3773 \\
\hline \hline Median family income (in dollars) & 42,534 & $35,119-49,949$ & .025 \\
\hline \hline Married parents & .60 & $.55-.65$ & .023 \\
\hline \hline Employed mother & .71 & $.67-.76$ & .026 \\
\hline \hline Religious & .52 & $.47-.57$ & .074 \\
\hline \hline Age at sexual initiation (in years) & 16 & $16-16$ & .023 \\
\hline \hline Child of a teen mother & .30 & $.26-.35$ & .116 \\
\hline \hline Age of mother at child's birth (in years) 21 & $20-21$ & \\
\hline
\end{tabular}


Table 2. Propensity score adjusted and unadjusted characteristics of analytic sample by gender role attitudes

\section{Before propensity adjustment After propensity adjustment}

\begin{tabular}{|c|c|c|c|c|c|c|}
\hline & Egalitarian & Moderate & Traditional & I Egalitarian & Moderate & e Traditional \\
\hline Religious & $45 \%$ & $47 \%^{\mathrm{a}}$ & $56 \%$ & $45 \%$ & $47 \%$ & $49 \%$ \\
\hline $\begin{array}{l}\text { African } \\
\text { American }\end{array}$ & $33 \%$ & $21 \%^{\mathrm{b}}$ & $21 \%$ & $25 \%$ & $21 \%$ & $21 \%$ \\
\hline $\begin{array}{l}\text { Urban } \\
\text { residence }\end{array}$ & $78 \%$ & $74 \%$ & $76 \%$ & $78 \%$ & $74 \%$ & $74 \%$ \\
\hline $\begin{array}{l}\text { Age at sexual } \\
\text { entry }\end{array}$ & 16.2 & 16.4 & 16.6 & 16.5 & 16.4 & 16.6 \\
\hline $\begin{array}{l}\text { Mother less } \\
\text { than HS }\end{array}$ & $17 \%$ & $18 \%$ & $16 \%$ & $17 \%$ & $18 \%$ & $16 \%$ \\
\hline $\begin{array}{l}\text { Mother works } \\
\text { fulltime }\end{array}$ & $62 \%$ & $60 \%$ & $64 \%$ & $62 \%$ & $60 \%$ & $61 \%$ \\
\hline Teen mother & $28 \%$ & $29 \%^{\mathrm{a}}$ & $36 \%$ & $32 \%$ & $29 \%$ & $32 \%$ \\
\hline In poverty & $33 \%$ & $15 \%^{\mathrm{b}}$ & $12 \%$ & $22 \%$ & $15 \%$ & $11 \%$ \\
\hline $\begin{array}{l}\text { Two parent } \\
\text { household }\end{array}$ & $55 \%$ & $60 \%$ & $56 \%$ & $57 \%$ & $60 \%$ & $56 \%$ \\
\hline
\end{tabular}

a) Statistically significant $(p<.05)$ difference between moderate and traditional attitudes.

b) Statistically significant $(p<.05)$ difference between moderate and egalitarian attitudes. 
Table 3. Gender role attitudes effects on risky sexual behavior among young women, based on radius neighbor matching ${ }^{\mathrm{a}}$

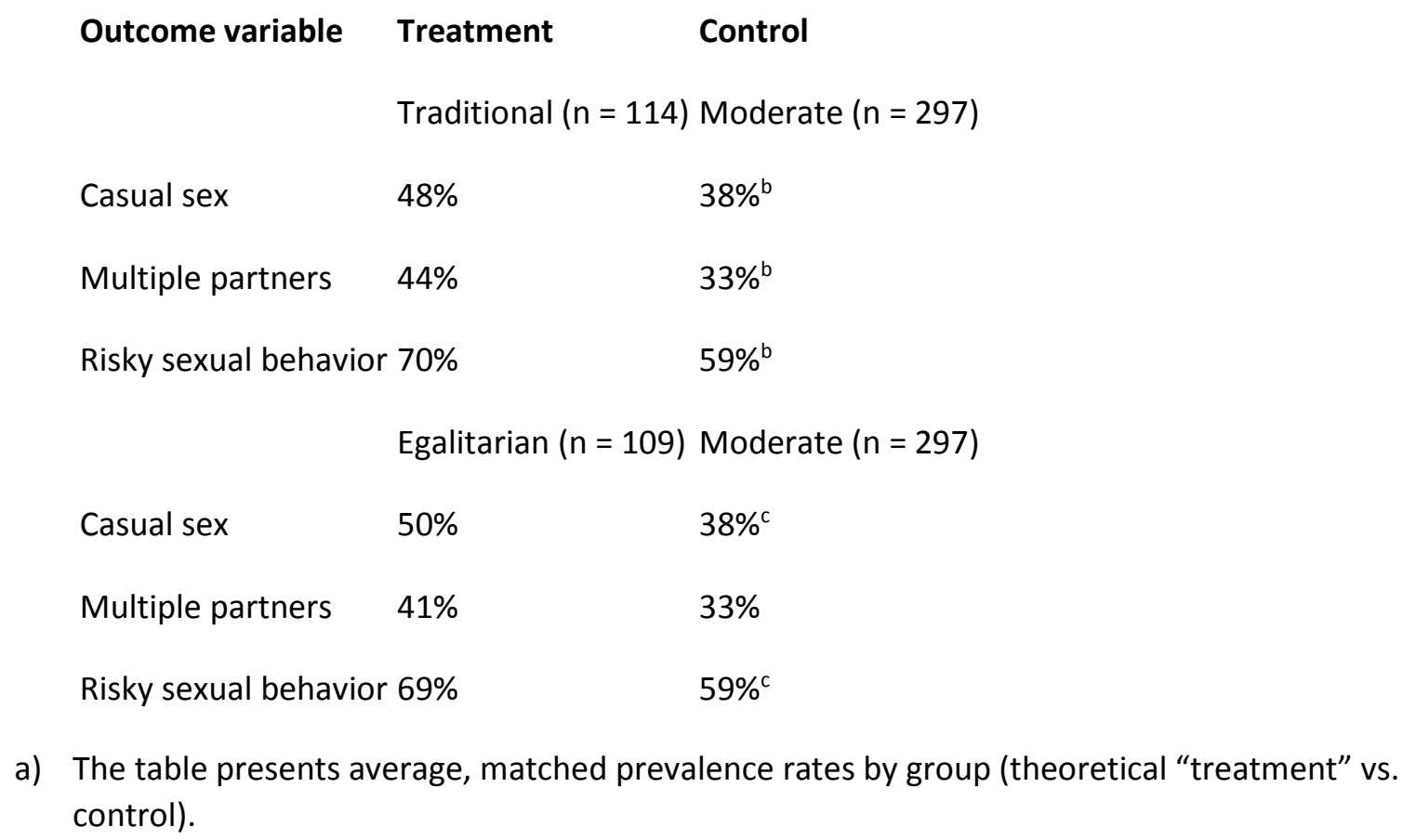

a) The table presents average, matched prevalence rates by group (theoretical "treatment" vs. control).

b) $p<.05$.

c) $p<.01$. 
Figure 1. Conceptual framework.

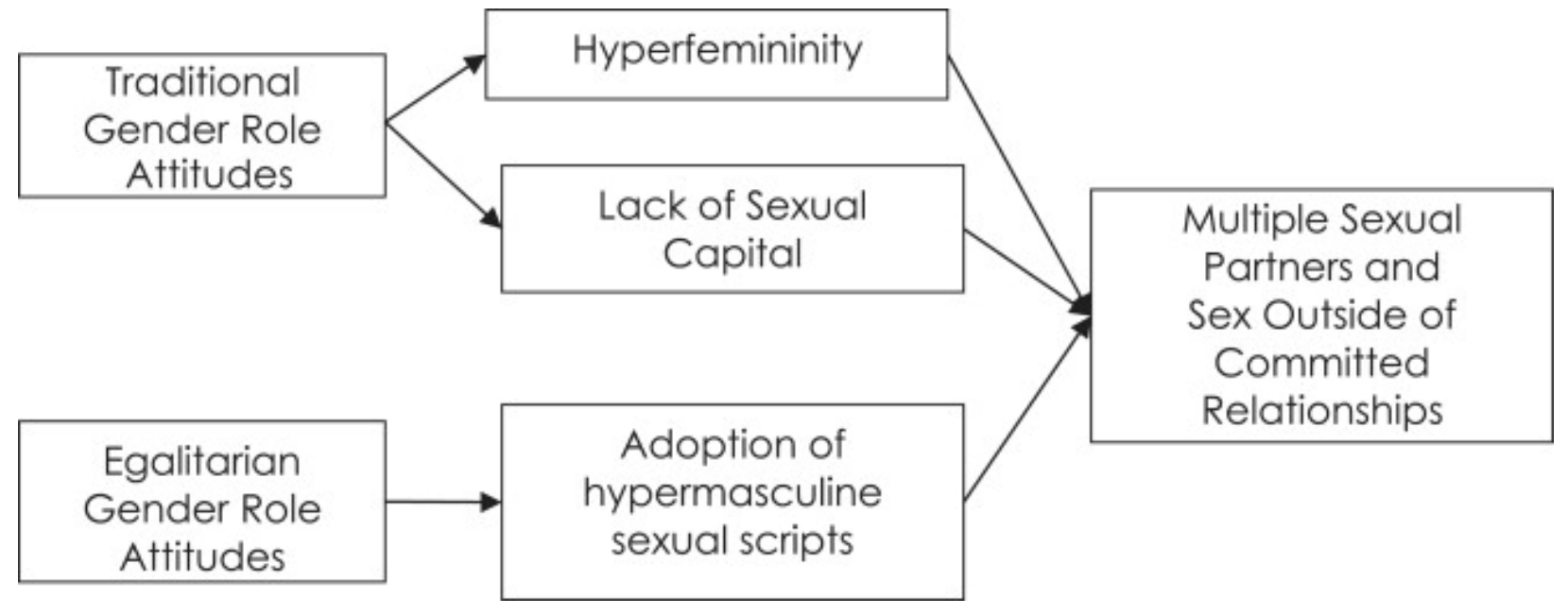

